\title{
Utilização de minerais iônicos ou complexos orgânicos de minerais no pré-parto de vacas Holandesas
}

\author{
[Use of ionic minerals or organic mineral complexes in the dry period of Holsteins cows] \\ C.G. Batista ${ }^{1}$, S.G. Coelho ${ }^{2}$, A.M.Q. Lana $^{2}$, E. Rabelo ${ }^{3}$ A.S. Araújo ${ }^{1}$, Z.I.P. Lobato ${ }^{2}$, \\ R.B. Reis ${ }^{2}$, H.M. Saturnino ${ }^{2}$ \\ ${ }^{1}$ Aluna de Pós Graduação - EV-UFMG, Belo Horizonte, MG \\ ${ }^{2}$ Escola de Veterinária - UFMG - Belo Horizonte, MG \\ ${ }^{3}$ ReHagro
}

\begin{abstract}
RESUMO
Os efeitos do uso de minerais complexados durante o pré-parto sobre a ocorrência de retenção de placenta foram avaliados em 135 vacas Holandesas de dois ou mais partos: grupo mineral iônico (69 animais) e grupo mineral complexado (66 animais). Em 55 desses animais foram também avaliadas as concentrações séricas da imunoglobulina $\mathrm{G}(\mathrm{IgG}), \mathrm{Zn}, \mathrm{Cu}$ e a qualidade do colostro. O experimento foi realizado em delineamento inteiramente ao acaso, em arranjo em parcelas subdivididas. As concentrações séricas de IgG e dos microminerais foram avaliadas por análise de variância, sendo utilizados, respectivamente, os testes de Duncan e Fisher. A taxa de erro $\alpha$ admitida foi de 7\%. Não foram observadas diferenças entre os grupos para ocorrência de retenção de placenta, qualidade do colostro, concentrações séricas de $\mathrm{Zn}$ e $\operatorname{IgG}$ $(\mathrm{P}>0,07)$, sendo observada diferença para a concentração de $\mathrm{Cu}(\mathrm{P}<0,07)$. As concentrações de $\operatorname{IgG}$ foram diferentes nas semanas pré-parto avaliadas $(\mathrm{P}<0,07)$.
\end{abstract}

Palavras-chave: cobre, imunoglobulinas, retenção de placenta, zinco

\begin{abstract}
The effects of the use of complex minerals on the occurrence of retained placenta during pre-partum were valued on 135 Holstein cows from two or more deliveries. The animals were divided in two groups: ionic mineral (69 animals) and complexed mineral (66 animals). In 55 of these animals serum concentrations of imunoglobulin $\mathrm{G}(\mathrm{IgG}), \mathrm{Zn}$ and $\mathrm{Cu}$ and colostrum quality were also evaluated. The experiment was conducted in complete randomized split-plot design, serum IgG and trace minerals were evaluated by analysis of variance and used, respectively, Duncan's test and Fisher. The a error rate of $7 \%$ was accepted. There were no differences between groups for the occurrence of retained placenta, colostrum quality and serum concentrations of $\mathrm{Zn}$ and $\operatorname{Ig} G(P>0.07)$, a difference was observed for $C u(P<0.07)$ concentrations. The IgG concentrations were different on the weeks pre partum evaluated $(P<0.07)$.
\end{abstract}

Keywords: cupper, immunoglobulin, placenta retention, zinc

\section{INTRODUÇÃO}

O parto e o início da lactação são períodos de grande estresse para vacas de leite devido aos desafios metabólicos que ocorrem nesse período. Nas últimas duas semanas pré-parto, as vacas de leite geralmente estão em balanço negativo de energia e cálcio, e nos últimos dias que antecedem o parto, o balanço de outros nutrientes, tais como proteína, vitaminas e minerais, também pode ser comprometido. A principal razão desse balanço negativo de nutrientes é o contínuo decréscimo no consumo de matéria seca (MS) (Bertics et al., 1992; Santos, 1996), associado ao aumento nas demandas de nutrientes para crescimento fetal e

Recebido em 4 de abril de 2011

Aceito em 23 de maio de 2012

E-mail: sandragesteiracoelho@gmail.com 
síntese de colostro (Davis et al., 1979; Bell, 1995). O aumento das demandas de nutrientes aumenta também as exigências de oxigênio e resulta na produção de espécies reativas ao oxigênio, que podem exceder a capacidade antioxidante endógena, levando ao estresse oxidativo (Weiss, 1998). Baixas concentrações sanguíneas de selênio, zinco e cobre também estão associadas com aumento no estresse oxidativo e redução na atividade leucocitária, uma vez que esses elementos exercem papel antioxidante (Weiss, 1990; Erskine, 1993). O estresse oxidativo aumenta a susceptibilidade, especialmente das vacas no período de transição, a uma variedade de problemas de saúde, tais como imunodeficiência, mastites, retenção de placenta, infertilidade, entre outros (Goff, 2006; Sordillo e Aitken, 2009).

A retenção de placenta tem sido associada a falhas na função dos neutrófilos (Kimura et al., 2002) e macrófagos (Miyoshi et al., 2002). O efeito da suplementação com antioxidantes sobre a retenção de placenta provavelmente envolve melhora na função imune com maior capacidade reativa de neutrófilos (Spears e Weiss, 2008), uma vez que a redução na atividade leucocitária está relacionada principalmente com a capacidade dos leucócitos em destruir e eliminar bactérias após fagocitose (Erskine, 1993).

A presença de concentrações adequadas de substâncias antioxidantes, derivadas de vitaminas e microminerais, tem como função impedir que os radicais livres presentes no citosol da célula causem danos à própria estrutura física e química da célula, reduzindo, assim, a taxa de destruição celular (Santos, 1996).

A infertilidade em vacas de leite é um problema complexo, multifatorial, que não pode ser avaliado isoladamente de outras doenças ou desordens fisiológicas. Macro, micro- minerais e vitaminas possuem papel vital para prevenir essas desordens no período peri-parto. Com base nas funções gerais dos macro e microelementos, pode-se afirmar, como regra geral, que toda deficiência mineral capaz de produzir alterações na saúde e no metabolismo do animal tende a interferir, também com alguma intensidade, no seu desempenho reprodutivo (Hurley e Doane, 1989; Guthrie e West, 2008).
Os minerais que, geralmente, afetam a reprodução em bovinos estão classificados na categoria dos microminerais, mas Ca e P também podem estar envolvidos (Boland, 2003).

Os minerais "orgânicos", quelatados ou complexados, têm sido desenvolvidos com a finalidade de garantir a absorção do mineral no trato intestinal, sem entrar no processo de competição iônica (pressão iônica da mucosa intestinal), normalmente determinada pela presença de maior concentração dos íons minerais. $\mathrm{O}$ interesse no uso desses minerais se deve a relatos de melhora no desempenho animal, como ganho de peso, eficiência de conversão alimentar, alteração na composição da carcaça, aumento na produção de leite, ou mesmo a percepção de melhorias em saúde e desempenho reprodutivo de fêmeas bovinas (Santos, 2006). Ainda, Swecker et al. (1995) reportam que suplementação com selênio no pré-parto (120mg de $\mathrm{Se} / \mathrm{kg}$ da mistura mineral) aumentou a concentração de IgG no colostro e a sua absorção em bezerros de corte. Em adição a seu valor imunológico, o colostro é uma excelente fonte de nutrientes para o neonato por conter grande quantidade de proteína, energia, minerais e vitaminas.

Dessa forma, o objetivo deste trabalho foi estudar os efeitos da utilização de minerais complexados durante o pré-parto sobre a ocorrência de retenção de placenta, qualidade de colostro e as concentrações séricas de imunoglobulinas ( $\mathrm{IgG}), \mathrm{Zn}$ e $\mathrm{Cu}$.

\section{MATERIAL E MÉTODOS}

Todos os procedimentos experimentais foram aprovados pelo Comitê de Ética em Experimentação Animal da Universidade Federal de Minas Gerais (CETEA/UFMG), certificado $n^{\circ}$ 43/2007.

O experimento foi realizado em uma propriedade leiteira comercial, no município de Inhaúma, no período de maio a outubro de 2007. Foram utilizadas 135 vacas da raça Holandesa de segunda ou mais ordens de lactação, distribuídas ao acaso nos grupos: mineral iônico (69 animais) e grupo mineral complexado (66 animais). As duas misturas minerais foram formuladas para conter quantidades similares de macro e 
microminerais (Tortuga Cia. Zootécnica Agrária, São Paulo, Brasil).

A mistura mineral iônico foi formulada apenas com fontes inorgânicas de minerais: carbonato de cálcio, fosfato bicálcico, cloreto de sódio, iodeto de cálcio, sulfato de cobalto, sulfato de cobre, fosfato de ferro, sulfato de manganês, cloreto de potássio, selenito de sódio, sulfato de zinco, cloreto de cromo e óxido de magnésio. $\mathrm{Na}$ mistura mineral complexado, as fontes inorgânicas de selênio, zinco, cobre, enxofre, manganês e cromo foram substituídas por fontes orgânicas. Para a obtenção das fontes orgânicas, os microminerais foram industrialmente misturados a peptídeos purificados de soja e, posteriormente, fermentados por cultura de leveduras, produzindo os carboquelatos de zinco, cobre, enxofre, manganês, cobalto e selênio.

Todos os animais foram alojados, aproximadamente, 42 dias antes do parto em piquetes de braquiária (Brachiaria decumbes), de $40 \times 30 \mathrm{~m}^{2}$, com aproximadamente 11 animais cada, recebendo, a partir daí, as dietas experimentais na forma de dieta completa. As dietas foram formuladas de acordo com as recomendações do NRC (Nutrient..., 2001) (Tab. 1) e foram oferecidas às nove e 17 horas. A água foi fornecida à vontade, em tanques com capacidade de 200 litros. Os partos ocorreram nos piquetes e foram monitorados a cada hora. A placenta foi considerada retida quando a expulsão não ocorreu até 12 horas após o parto.

Tabela 1. Composição, quantidade e ingredientes da dieta oferecida na maternidade

\begin{tabular}{lcc}
\hline \multicolumn{1}{c}{ Ingrediente } & Quantidade/animal (kg) & MS $(\mathrm{kg})$ \\
\hline Tifton verde & 7,00 & 1,80 \\
Farelo de soja & 2,00 & 1,78 \\
Polpa cítrica & 0,30 & 0,26 \\
Silagem de milho & 23,90 & 7,30 \\
Mistura pré-parto/ingredientes & 1,00 & \\
& & 0,66 \\
$\quad$ Milho moído & 0,09 & \\
$\quad$ Fosfato bicálcico & 0,12 & \\
$\quad$ Sulfato de magnésio & 0,05 & \\
$\quad$ Premix vitamínico ADE*** & 0,02 & 34,80 \\
$\quad$ Premix mineral iônico e complexado & 0,03 & 14,65 \\
$\quad$ Sal comum & 0,03 & 47,88 \\
Total da dieta & 34,2 & 27,17 \\
Matéria seca & & 4,90 \\
Proteína bruta & & 64,38 \\
FDN & & 6,22 \\
FDA & & 0,55 \\
Extrato etéreo & & 0,26 \\
NDT & & 0,00 \\
Minerais & & 0,02 \\
Cálcio (ppm) & & 0,02 \\
Fósforo (ppm) & & \\
Cobalto (ppm) & & \\
Zinco (ppm) & & \\
\hline
\end{tabular}

***Premix ADE: cobalto 200mg, cobre $10000 \mathrm{mg}$, manganês $14000 \mathrm{mg}$, zinco 43000mg, se 290mg, iodo 500mg, vit A 4000000UI, vit D3 11000000UI, vit E 27000UI, monensina, 13000mg, enxofre 500mg, biotina 870mg.

Em 55 animais, 28 do grupo mineral iônico e 27 do mineral complexado, amostras de sangue de $20 \mathrm{~mL}$ foram obtidas em tubos de vacutainer com ativador de coágulo, na veia mamária, aos 42 dias pré-parto e semanalmente até o dia do parto, para avaliação de IgG sérica, e 28 dias pré-parto 
e semanalmente, para avaliação das concentrações de $\mathrm{Zn}$ e $\mathrm{Cu}$. Imediatamente após as colheitas, as amostras foram centrifugadas a 3.000RPM por 15 minutos, sendo o soro removido e congelado a $-20^{\circ} \mathrm{C}$.

Nesses mesmos animais, duas amostras de colostro foram obtidas, uma hora após o parto, por ordenha manual, antes da colostragem dos bezerros. Uma amostra de $50 \mathrm{~mL}$ foi utilizada para mensurar a qualidade do colostro, com a utilização de colostrômetro, de acordo com escala proposta por Fleenor e Stott (1980): até $21,8 \mathrm{mg} / \mathrm{mL}$ de imunoglobulinas, colostro de baixa qualidade; de 22 a 49,8mg/mL, qualidade intermediária; e acima desse valor, colostro de alta qualidade. A outra amostra de $10 \mathrm{~mL}$ foi colhida e congelada em freezer $\left(-20^{\circ} \mathrm{C}\right)$ para posterior análise de IgG.

As concentrações séricas de $\mathrm{Cu}$ e $\mathrm{Zn}$ foram determinadas por espectrometria de absorção atômica (Perkin-Elmer AAS 5000).

Para as análises de $\operatorname{IgG}$ no soro e colostro, utilizou-se o teste de imunodifusão radial (IDR), segundo Mancini et al. (1965) e Fleenor e Stott (1981). IgG de bovino purificada foi utilizada para construção da curva padrão, sendo o intervalo de detecção estipulado entre 9,35 e $71 \mathrm{mg} / \mathrm{mL}$; a curva foi construída no software ORIGEN®.

Nas amostras pré-secas dos alimentos, determinaram-se matéria seca em estufa a $105^{\circ} \mathrm{C}$ (Official..., 1980), proteína bruta pelo método de Kjeldhal, segundo o AOAC (Official..., 1980), componentes da parede celular pelo método sequencial de Van Soest et al. (1991) e cálcio e fósforo, segundo o AOAC (Official..., 1980). Os minerais nas amostras de sal complexado e iônico foram determinados no laboratório Silicon, em São Paulo.

O experimento foi realizado em delineamento inteiramente ao acaso, em arranjo em parcelas subdivididas, com o tipo de mineral na parcela e o tempo na subparcela. Para testar as diferenças entre as médias de $\operatorname{IgG}$ no soro sanguíneo das vacas, usou-se o teste de Duncan a $7 \%$ de probabilidade. Para testar as diferenças entre as médias do mineral no soro sanguíneo, usou-se o teste de Fisher a $7 \%$ de probabilidade. Os dados referentes à retenção de placenta e à qualidade de colostro avaliada pelo colostrômetro foram analisados pelo teste do qui-quadrado a $5 \%$ de probabilidade.

\section{RESULTADOS E DISCUSSÃO}

As concentrações de Zn no soro das vacas, nas semanas anteriores ao parto e ao parto, não foram diferentes entre grupos e entre tempos, e não houve interação grupo versus tempo ( $\mathrm{P}>0,07)$ (Tab. 2). Já as concentrações de $\mathrm{Cu}$ foram maiores em todas as semanas avaliadas nos animais que receberam minerais complexados $(\mathrm{P}<0,07)$. As concentrações de $\mathrm{Zn}$ e $\mathrm{Cu}$ nos dois grupos estão dentro dos valores considerados normais e próximas às relatadas por Kincaid e Socha (2007), utilizando-se minerais complexados.

Neste experimento, os minerais complexados foram oferecidos aos animais, em média, seis semanas antes do parto, sendo esse tempo suficiente para provocar alterações nas concentrações séricas de $\mathrm{Cu}$, mas não de $\mathrm{Zn}$.

A concentração de $\operatorname{IgG}$ sérica não foi diferente entre os grupos e não ocorreu interação grupo versus semana avaliada $(\mathrm{P}>0,05)$, sendo as concentrações de IgG diferentes apenas entre as semanas avaliadas $(\mathrm{P}<0,05)$ (Fig. 1). A concentração média de IgG no soro apresenta taxa de redução semanal até $o$ parto de $2,74 \mathrm{mg} / \mathrm{dL}$, sendo os valores observados estatisticamente diferentes na segunda e primeira semanas pré-parto. Este comportamento também foi descrito por Brandon et al. (1971), que observaram $50 \%$ de redução, duas a três semanas antes do parto, e por Guy et al. (1994), que relataram queda maior na concentração de $\mathrm{IgG}$ no soro 13 dias antes do parto, chegando ao mínimo entre seis dias e o dia do parto. A queda na concentração de IgG no soro próximo ao parto ocorre devido ao transporte das imunoglobulinas para a glândula mamária para a formação do colostro. Segundo Brandon et al. (1971), os valores da IgG retornam à concentração normal quatro semanas após o parto. A concentração sérica média de $\operatorname{IgG}$ de $23,2 \mathrm{mg} / \mathrm{mL}$ é próxima à relatada por Gapper et al. (2007), de $25 \mathrm{mg} / \mathrm{mL}$. A redução nas concentrações de $\operatorname{IgG}$ nas semanas anteriores ao parto se apresenta dentro de padrões normais. 


\section{Batista et al.}

Tabela 2. Concentração média e desvio-padrão de $\mathrm{Zn}$ e $\mathrm{Cu}(\mu \mathrm{g} / \mathrm{mL})$ no soro de vacas leiteiras que receberam minerais iônicos ou complexados nas semanas anteriores ao parto

\begin{tabular}{ccc}
\hline Dias & Mistura mineral iônico & Mineral complexado \\
\hline-28 & $0,88 \pm 0,34$ & $\mathrm{Zn}(\mu \mathrm{g} / \mathrm{mL})^{1}$ \\
-21 & $0,89 \pm 0,33$ & $0,92 \pm 0,28$ \\
-14 & $1,05 \pm 0,35$ & $0,96 \pm 0,31$ \\
-7 & $0,90 \pm 0,13$ & $0,89 \pm 0,28$ \\
Parto & $0,89 \pm 0,31$ & $0,93 \pm 0,31$ \\
Média & $0,93 \pm 0,32$ & $1,03 \pm 0,55$ \\
\hline & & $0,95 \pm 0,36$ \\
\hline-28 & $0,61 \pm 0,15 \mathrm{~B}$ & \\
-21 & $0,61 \pm 0,10 \mathrm{~B}$ & $\mathrm{Cu}(\mu \mathrm{g} / \mathrm{mL})^{2}$ \\
-14 & $0,61 \pm 0,14 \mathrm{~B}$ & $0,66 \pm 0,15 \mathrm{~A}$ \\
-7 & $0,53 \pm 0,42 \mathrm{~B}$ & $0,66 \pm 0,16 \mathrm{~A}$ \\
Parto & $0,61 \pm 0,15 \mathrm{~B}$ & $0,73 \pm 0,16 \mathrm{~A}$ \\
Média & $0,60 \pm 0,14 \mathrm{~B}$ & $0,62 \pm 0,11 \mathrm{~A}$ \\
\hline
\end{tabular}

Médias seguidas de letras distintas, nas linhas, diferem pelo teste de Fisher ( $\mathrm{P}<0,07)$. Zinco CV: 25,8; Cobre CV: 24,3 .

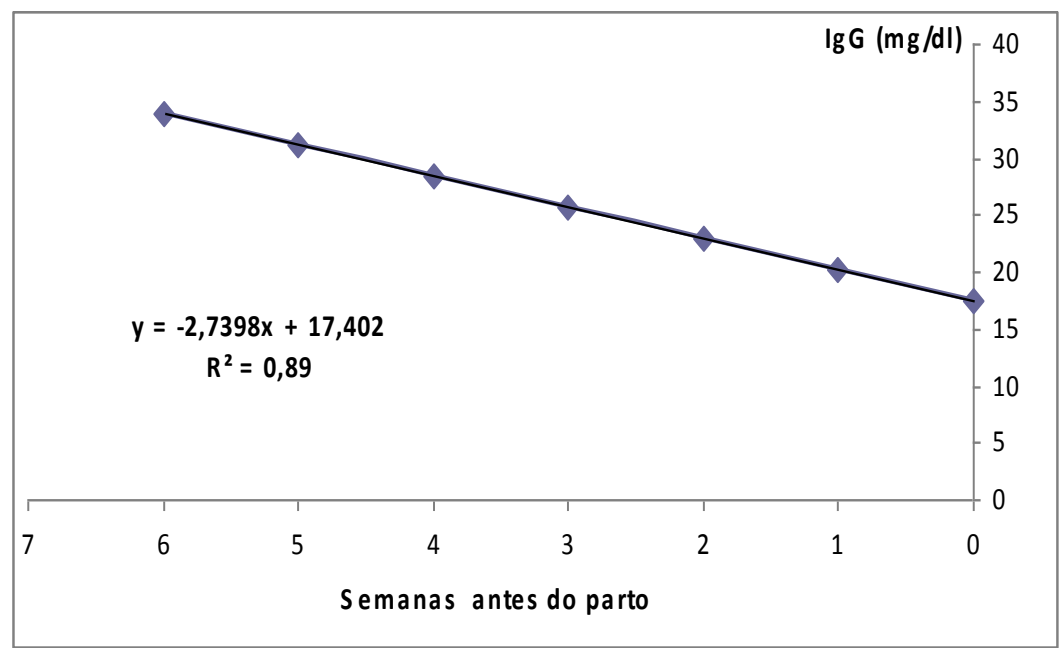

Figura1. Concentração sérica de IgG nas semanas anteriores ao parto em vacas leiteiras.

Todos os partos ocorreram de forma normal. A ocorrência de retenção de placenta, a qualidade do colostro avaliada pelo colostrômetro e pela técnica de imunodifusão radial não foram diferentes entre os animais que receberam mistura de minerais iônicos ou complexados $(\mathrm{P}>0,05)$ (Tab. 3).

Vários fatores têm sido apontados como causas de retenção de placenta, entre eles deficiências de macro e microminerais e alterações na resposta imune. Os animais receberem a mistura com minerais complexados, aproximadamente, nas seis semanas anteriores ao parto; as concentrações séricas de $\mathrm{Cu}$ foram alteradas, mas não refletiram em redução na ocorrência de retenção de placenta e na melhora da qualidade do colostro.

A concentração média de IgG encontrada no colostro dos dois grupos foi de $79,9 \pm 24,9 \mathrm{mg} / \mathrm{mL}$; este valor está dentro da faixa considerada normal (Gapper et al., 2007). 
Tabela 3. Qualidade do colostro avaliada por colostrômetro e concentração de $\operatorname{IgG} \mathrm{mg} / \mathrm{mL}$, avaliada por imunodifusão radial, e ocorrência de retenção de placenta em vacas que receberam, no período pré-parto, mineral iônico ou complexado

\begin{tabular}{|c|c|c|c|c|c|}
\hline Grupo & Concentração de & \multicolumn{3}{|c|}{ Qualidade do colostro $^{2}$} & Retenção de \\
\hline & & $<20 \mathrm{mg} / \mathrm{dL}$ & $\begin{array}{l}>20 \mathrm{mg} / \mathrm{dL} \\
<50 \mathrm{mg} / \mathrm{dL}\end{array}$ & $>50 \mathrm{mg} / \mathrm{dL}$ & \\
\hline Mineral iônico & $72,6 \pm 24,1$ & $\begin{array}{c}11 / 28 \\
(39,3 \%)\end{array}$ & $\begin{array}{c}3 / 28 \\
(10,7 \%)\end{array}$ & $\begin{array}{l}14 / 28 \\
(50 \%)\end{array}$ & $14 / 69(20,3 \%)$ \\
\hline $\begin{array}{c}\text { Mineral } \\
\text { complexado }\end{array}$ & $86,8 \pm 24,5$ & $5 / 28(18,5 \%)$ & $\begin{array}{l}18 / 28 \\
(60 \%)\end{array}$ & $\begin{array}{l}18 / 28 \\
(60 \%)\end{array}$ & $8 / 66(12,1 \%)$ \\
\hline
\end{tabular}

${ }^{1}$ Teste de Duncan (P>0,07); concentração de IgG CV: 30,7. ( ) frequência relativa; ${ }^{2}$ Teste de qui-quadrado $(\mathrm{P}>0,05)$

\section{CONCLUSÕES}

A utilização de complexos de minerais para vacas no pré-parto, por um período de aproximadamente 42 dias antes do parto, não alterou a qualidade do colostro, as concentrações séricas de IgG e $\mathrm{Zn}$ e a ocorrência de retenção de placenta. Contudo, este estudo demonstrou aumento na concentração de cobre sérico com a utilização de complexos orgânicos, o que pode indicar diferenças no tempo de suplementação para os diferentes minerais, merecendo, dessa forma, novas investigações.

\section{AGRADECIMENTOS}

Os autores agradecem à fazenda São João, por permitir realizar este experimento em suas instalações, à Tortuga, pelo apoio para realização deste experimento e à Escola de Engenharia da UFMG, pelas análises de minerais no soro dos animais.

\section{REFERÊNCIAS}

BELL, A.W. Regulation of organic nutrient metabolism during transition from late pregnancy to early lactation. J. Anim. Sci., v.73, p.2804-2819, 1995.

BERTICS, S.J.; GRUMMER, R.R.; CADORNINGA-VALINO, C. et al. Effect of prepartum dry matter intake on liver triglyceride concentration in early lactation. J. Dairy Sci., v.75, p.1914-1922, 1992.

BOLAND, M.P. Trace minerals in production and reproduction in dairy cows. Adv. Dairy Tech., v.15, p.319-330, 2003.
BRANDON, M.R.; WATSON, D.L.; LASCELLES, A.K. The mechanism of transfer of immunoglobulin into mammary secretions of cow. Aust. J. Exp. Biol. Med. Sci., v.49, p.613623,1971

DAVIS, A.J.; FLEET, R.J.A.; GOODE, M.H. et al. Changes in mammary gland function at the onset of lactation in the goat: correlation with hormonal changes. J. Physiol, v.288, p.33-44, 1979.

ERSKINE, R.J. Nutrition and mastitis. Vet. Clin. N. Am.: Food Anim. Pract., v.9, p.551-561, 1993.

FLEENOR, W.A.; STOTT, G.H. Hydrometer test for estimation of immunoglobulin concentration in bovine colostrum. J. Dairy Sci., v.63, p.973-977, 1980.

FLEENOR, W.A.; STOTT, G.H. Single radial immunodiffusion analysis for quantitation of colostral immunoglobulin concentration. J. Dairy Sci., v.64, p.740-747, 1981.

GAPPER, L.W.; COPESTAKE, D.E.J.; OTTER, D.E. et al. Analysis of bovine immunoglobulin $\mathrm{G}$ in milk, colostrum and dietary supplements: a review. Anal. Bioanal. Chem., v.389, p.93-109, 2007.

GOFF, J.P. Major advances in our understanding of nutritional influences on bovine health. $J$. Dairy Sci., v.89, p.1292-1301, 2006. 
GUTHRIE, L.D.; WEST, J.W. Nutrition e reproduction interactions in dairy cattle. The University of Georgia College of Agricultural e Environment Science Cooperative Extension Service, 2008. Disponível em: <http://www.ahdairy.com/uploads/articles/ nutritionreproductioninteractionsindairycattle.pdf Acesso em: 08 fev. 2009.

GUY, M.A.; McFADDEN, T.B.; COCKRELL, D.C. et al. Regulation of colostrum formation in beef and dairy cows. J. Dairy Sci., v.77, p.3002-3007, 1994.

HURLEY, W.L.; DOANE, R.M. Recent developments in the roles of vitamins and minerals in reproduction. J. Dairy Sci., v.72, p.784-804, 1989.

KIMURA, K.; GOFF, J.P.; KEHRLI, M.E. Jr. et al. Decreased neutrophil function as a cause of retained placenta in dairy cattle. J. Dairy Sci., v.85, p.544-550, 2002.

KINCAID, R.L.; SOCHA, M.T. Effect of cobalt supplementation during late gestation and early lactation on milk and serum measures. J. Dairy Sci., v.90, p.1880-1886, 2007.

MANCINI, G.; CARBONARA, A.O.; HEREMSANS, J.F. Immunochemical quantitation of antigens by single radial immunodiffusion. Immunochemistry, v.2, p.235-254, 1965.

MIYOSHI, M.; SAWAMUKAI, Y.; IWANAGA, T. Reduced phagocytotic activity of macrophages in the bovine retained placenta. Reprod. Domest. Anim., v.37, p.53-56, 2002.

NUTRIENT requirements of dairy cattle. 7.ed. Washington: National Academy of Sciences, 2001. 381p.

OFFICIAL methods of analysis. 13.ed. Washington: AOAC, 1980. 1015p.
SANTOS, J.E.P. Effect of degree of fatness prepartum on lactation performance and ovarian activity of early postpartum dairy cows. 1996. 120f. Thesis. (Ph.D). Dept. Animal Sciences, University of Arizona, Tucson, AZ.

SANTOS, J.E.P. Efetividade do uso de minerais orgânicos para bovinos. In: SIMPÓSIO SOBRE NUTRIÇÃO DE BOVINOS, 8., 2006, Piracicaba. Anais... Piracicaba:FEALQ, 2006. p.191-213.

SORDILLO, L.M.; AITKEN, S.L. Impact of oxidative stress on the health and immune function of dairy cattle. Vet. Immunol. Immunopathol., v.128, p.104-109, 2009.

SPEARS, J.W.; WEISS, W.P. Role of antioxidants and trace elements in health and immunity of transition dairy cows. Vet. J., v.176, p.70-76, 2008.

SWECKER, W.S.; THATCHER, C.D.; EVERSOLE, D.E. et.al. Effect of selenium supplementation on colostral IgG concentration in cows grazing selenium deficient pastures and on postsuckle serum IgG concentration in their calves. Am. J. Vet. Res., v.56, p.450-453, 1995.

VAN SOEST, P.J.; ROBERTSON, J.B.; LEWIS, B.A. Methods for dietary fiber, neutral detergent fiber, and non starch polysaccharides in relation to animal nutrition. J. Dairy Sci., v.74, p.35833597, 1991.

WEISS, W.P. Effect of duration of supplementation of selenium and vitamin $\mathrm{E}$ on periparturient dairy cows. J. Dairy Sci., v.73, p.3187-3194, 1990 .

WEISS, W.P. Requirements of fat-soluble vitamins for dairy cows: A review. J. Dairy Sci., v.81, p.2493-2501, 1998. 